\title{
Interest of a standardized hypnotic message for the reduction of pain and anxiety in cancer patients treated by capsaicin patch for neuropathic pain: $A$ randomized-controlled trial
}

\section{Rémi Etienne}

Institut de Cancérologie de Lorraine

Myriam Laurent

Institut de Cancérologie de Lorraine

Aline Henry

Institut de Cancérologie de Lorraine

Antoine Bioy

Paris 8 University

Julia Salleron ( $\nabla$ j.salleron@nancy.unicancer.fr )

Institut de Cancérologie de Lorraine

Cécile Huin-Schohn

Institut de Cancérologie de Lorraine

Nathalie Cretineau

Institut de Cancérologie de Lorraine

\section{Research Article}

Keywords: cancer, pain, anxiety, hypnosis, music therapy

Posted Date: February 23rd, 2021

DOI: https://doi.org/10.21203/rs.3.rs-147663/v1

License: (c) (i) This work is licensed under a Creative Commons Attribution 4.0 International License.

Read Full License 


\section{Abstract}

\section{Background}

Neuropathic pain is characterised by spontaneous painful symptoms. Medical therapies include the use of a capsaicin $8 \%$ patch (Qutenza ${ }^{\circledR}$, Grünenthal Gmbh, Germany), and patients may experience a sharp burning sensation at application and removal of the patch. This study aimed to evaluate the impact of playing a standardized hypnosis recording during application, on the pain and anxiety induced by capsaicin treatment.

\section{Methods}

In a randomized-controlled trial, we assessed the benefits of the intervention firstly on pain and secondly on anxiety, as measured using numerical rating scales. All patients had application of the capsaicin patch, including the possibility for the patient to apply a cold patch. Participants were randomly assigned to one of 3 groups, namely the "Standard group" (no intervention), "Hypnosis group", in which a standardized hypnotic message was played during application, or the "Music group" in which relaxing music was played during application of the patch.

\section{Results}

Sixty-nine patients were included. Overall, there was no significant difference in pain scores between groups $(p=0.355)$. Compared to standard application, anxiety was significantly lower in the hypnosis group after application $(p=0.007)$, with no significant difference between the standard and music arms $(p=0.271)$, or between the hypnosis and music arms $(p=0.423)$.

\section{Conclusions}

Listening to a standardized hypnotic message during application of a capsaicin patch was found to significantly lower anxiety. These findings indicate that the use of a hypnotic message can reduce discomfort and warrant its evaluation in other indications of pain or anxiety during treatment procedures.

Trial Registration : NCT02822625

\section{Background}

The International Association for the Study of Pain (IASP) defines neuropathic pain (NP) as "pain that arises as a direct consequence of a lesion or disease affecting the somatosensory system". The world prevalence of NP in the general population varies from 6.9 to $10 \%$ [1]. NP can lead to a significant decline in quality of life, and represents a major public health challenge. In $60 \%$ of cases, NP is localized within a specific area of the body [2]. NP is characterised by specific symptoms that can associate sensations that are not specifically painful, but rather unpleasant (numbness, tingling, itching), with spontaneous painful symptoms (stabbing pain, feeling of pressure, burning or electric shock sensation, but also 
allodynia or hyperalgesia) as well as negative sensory signs (impaired perception of mechanical or thermal stimuli)[1].

Improvements in our understanding of the pathophysiology of NP have led to the emergence of medical and non-medical therapies which are generally proposed in a pluridisciplinary context. Medical therapies include the use of local topical applications such as $5 \%$ lidocaine, plasters or an $8 \%$ capsaicin patch (Qutenza ${ }^{\circledR}$, Grünenthal Gmbh, Germany) [3]. Capsaicin is a highly selective agonist of transient receptor potential vanilloid 1 (TRPV1), which is present in the skin and essential for pain signalling [4]. The capsaicin patch is indicated in association with other antalgic agents in the management of peripheral NP that is localized, assessable and restricted to a limited area, in non-diabetic adults.

Despite the agonistic activity, exposure to capsaicin applied topically at high doses leads to initial activation of nociceptive nerve fibres expressing TRPV1, causing a burning sensation and erythema. Then, after exposure to capsaicin, TRPV1-containing sensory axons are desensitised, with downregulation of TRPV1 expression. Consequently, cutaneous nociceptors become less sensitive, leading to pain relief. The changes induced in cutaneous nociceptors by capsaicin are reversible and their normal function can be restored within a few weeks [5]. The most commonly described adverse effects (AEs) include a sharp burning sensation at the application and removal of the patch, as well as erythema and itching $[6,7]$. Although these AEs are transient and totally reversible, they may increase discomfort, leading to premature removal of the patch in 2 to $6 \%$ of patients [8].

The difficulty of controlling these AEs prompted us to envisage the use of therapeutic hypnosis as a complementary strategy on top of standard treatment, which generally associates the use of painkillers with application of cold. According to the American Psychological Association, therapeutic hypnosis can be defined as a state of consciousness involving focused attention and reduced peripheral awareness characterized by an enhanced capacity for response to suggestion. Since the end of the 1990s, the field of neurosciences has confirmed the existence of a unique neurological functioning occurring during hypnosis, notably by demonstrating how suggestions of pain relief can modify the sensory and affective components of the pain process [9]. Numerous studies have now demonstrated the positive impact of therapeutic hypnosis for pain management [10], in particular to reduce pain and anxiety in patients with burns $[11,12]$.

We therefore sought to propose a hypnotic approach that would be able to relieve the burning sensations felt by patients receiving treatment with a capsaicin patch in the framework of follow-up for chronic neuropathic pain in relation to active cancer or its treatment (post-operative pain, chemotherapy-related toxicity). The aim of the study was to evaluate the impact of playing a standardized hypnosis recording during application of an $8 \%$ capsaicin patch, firstly on the pain induced by capsaicin treatment, and secondly, on the anxiety felt during application of the patch.

\section{Methods}




\section{Study design and oversight}

We performed a randomized, single-centre, prospective pilot study in three parallel groups at the Institut de Cancérologie de Lorraine (ICL, Nancy, France). Participants were randomly assigned between groups in a 1:1:1 ratio : (1) application of the capsaicin patch according to standard procedure, which includes the possibility for the patient to apply a cold patch on the affected zone (Standard group); (2) application of the capsaicin patch according to the standard procedure, while at the same time playing a recording of a standardized hypnotic message (Hypnosis group); and (3) application of the capsaicin patch according to the standard procedure, accompanied by relaxing music (Music group). Randomization was centralized by computer-generated random numbers in blocks of six. The study was not blinded owing to the practical barriers to masking. The study design is illustrated in Fig. 1. This study adhered to the principles of the Declaration of Helsinki and guidelines of Good Clinical Practice. The safety and ethical conformity of the study have been reviewed and approved by the Ethics Committee (Comite de Protection des Personnes, CPP Est III) on 03/05/2016 under the number 16.03 .06 and by the National agency for the safety of medicines and health products on 22/04/2016 under the number 160228B-32. The study was also registered with the ClinicalTrials.gov Registry on 04/07/2016 under the number NCT02822625. All participants provided written informed consent.

\section{Inclusion and exclusion criteria}

All patients were attending the Interdisciplinary Unit for Supportive Care for Oncology Patients at ICL. Patients were eligible if they had neuropathic pain, and had previously had at least one application of a capsaicin patch, and had a new indication for capsaicin patch application. We excluded patients with psychotic disorders, patients with hearing disorders, patients unable to understand French, patients $<18$ years old, persons under judicial protection or legal guardianship, patients requiring premedication with painkillers before capsaicin patch application, and patients with a history of hypersensitivity to capsaicin or to any of the patch excipients.

\section{Interventions}

Patient screening was performed by the lead nurse from the pain management clinic (ML). After obtaining written informed consent, inclusion was performed on the day of the patch application in the outpatient unit. Then, patient randomization was performed. Study procedures were carried out in the same conditions for all patients, namely in the room located furthest away from the workstation in the unit, in order to minimize background noise, and to facilitate patient comfort and high-quality listening. In addition, a "Do not disturb" sign was placed on the door of the room to deter anyone from disturbing the patient during the time the patch was in place. The duration of capsaicin patch application was one hour. After patch removal, the patient was free to go home. A study nurse called the patient by phone at 72 hours after the patch application for the final evaluation of pain.

The hypnotic message was created and recorded by a nurse hypnotist (RE) at our institution who is qualified to train other hypnosis practitioners. The full script was read and amended by a renowned 
scientific expert in the field of medical hypnosis (AB). The text of the script included the different elements that characterise a hypnosis session, taking account of the rhythm of suggestions and the tone of voice, adapted to the progress of the study procedures and accommodating the constraints related to the monitoring of the patient. The therapeutic metaphor used in the recording was a walk in the mountains, with a dip in a lake of cool water. The story was aligned with the different stages of application of the capsaicin patch (blood pressure measurement, inclusion of outside sounds, duration of application). Numerous hypnosis techniques are proposed in the script in addition to the metaphors (confusion, acceptance, double-binds...). The hypnotic message was recorded in a professional recording studio in order to minimize background noise and optimize the quality.

The relaxing music was chosen by the study investigators based on the advice of a music therapist who works with patients suffering from pain. Three musical atmospheres were chosen (classical, easylistening and relaxing), in order to allow the patients to choose whichever type of music best corresponded to their expectations and personal tastes.

All recordings (hypnotic message and musical excerpts) were transferred to an MP3 player to make listening easier for the patient and played through a high-definition audio headset (NEW APPLE iPod Nano $16 \mathrm{Go}$ Space, APPLE $\left.{ }^{\circledR}\right)$.

\section{Outcome measures}

Assessments were conducted at 4 different times (see Fig. 1). Data recorded for the study purposes was entered into an electronic Case Report Form (CRF) (Cleanweb ${ }^{\circledR}$, Télémédecine SA Boulogne-Billancourt, France). We recorded gender, age, history of cardiovascular disease, pain and anxiety evaluations, patient's perception of the time the patch was in place, application of cold pack while the patch was in place. For patients randomized to Hypnosis group, we also noted whether the patient listened to the hypnotic message in its entirety (yes/no). For patients randomized to Music group, we noted the type of music the patient chose (classical, easy-listening, relaxing). The primary outcome was pain measured using a numerical rating scale (NRS). NRS is a one-dimensional measurement of pain intensity in adults. The NRS form was filled out by reporting scores verbally. The NRS score ranges from 0 to 10 , with 0 indicating no pain and 10 the worst imaginable pain. Higher scores on the NRS scale indicate a higher intensity of pain [13]. Secondary outcomes were anxiety measured using a NRS [14], with 0 indicating no anxiety and 10 the worst imaginable anxiety, and patient's perception of the time the patch (in minutes).

\section{Statistical methods}

Quantitative variables are described as mean \pm standard deviation (SD) if normally distributed, or median [interquartiles] if non-normally distributed, and were compared using ANOVA or the Kruskal-Wallis test. The normality of the distribution was investigated by the Shapiro-Wilks test. Qualitative variables are described as number (percentage) and were compared using the Chi square or Fisher's exact test as appropriate. 
The primary endpoint was pain as assessed by the NRS (from 0, corresponding to no pain, to 10 , intolerable pain) at the time of patch removal. Comparisons of pain and anxiety immediately after patch application and removal were performed by analysis of covariance (ANCOVA) in order to adjust for values prior to application. In case of differences across the three groups, Bonferroni correction was applied to account for multiple comparisons.

All analyses were performed using SAS version 9.4 (SAS Institute Inc., Cary, NC). All tests were two-sided and a $p$-value $<0.05$ was considered statistically significant.

The average pain score after application of a capsaicin patch is estimated at $6 \pm 2$ [7]. A difference of at least 2 points is considered clinically meaningful. Based on the hypothesis of an average pain score of 5 in the hypnosis group, and 7 in the control group, 23 patients were required in each group to show a significant difference with power of $80 \%$ and an alpha risk of $1.6 \%$ (after Bonferroni correction to account for the three groups), i.e. 69 patients in total.

\section{Results}

\section{Patients}

From August 2016 to July 2019, a total of 69 patients were included; 23 were randomized to each arm (Fig. 2). Fourteen participants were men (20\%), 55 (80\%) were women. The baseline characteristics of the study population are shown in Table 1. There was no significant difference between groups in terms of age, history of cardiovascular disease, presence of signs or symptoms at inclusion or ongoing treatment. There was also no significant difference between groups in the level of pain or anxiety before the patch was applied (Table 1). 
Table 1

Baseline characteristics of the study population according to randomization group.

\begin{tabular}{|c|c|c|c|c|c|}
\hline & $\begin{array}{l}\text { TOTAL } \\
\mathrm{N}=69\end{array}$ & $\begin{array}{l}\text { STANDARD } \\
\mathrm{N}=23\end{array}$ & $\begin{array}{l}\text { HYPNOSIS } \\
\mathrm{N}=23\end{array}$ & $\begin{array}{l}\text { MUSIC } \\
N=23\end{array}$ & $\begin{array}{l}\mathrm{p}- \\
\text { value }\end{array}$ \\
\hline Gender, $\mathrm{n}(\%)$ & 14(20.3) & $6(26.1)$ & $3(13)$ & $5(21.7)$ & 0.534 \\
\hline \multicolumn{6}{|l|}{ Males } \\
\hline Females & $55(79.7)$ & 17(73.9) & $20(87)$ & 18(78.3) & \\
\hline Age (years), mean \pm SD & $57.4 \pm 12.8$ & $58.7 \pm 13$ & $53.3 \pm 14.9$ & $58.7 \pm 10$ & 0.265 \\
\hline History of cardiovascular disease & $25(36.2)$ & $11(47.8)$ & 7(30.4) & $7(30.4)$ & 0.366 \\
\hline $\begin{array}{l}\text { Ongoing cardiovascular treatment } \\
\text { at inclusion }{ }^{+}\end{array}$ & $22 / 25(88.0)$ & 11/11(100) & $5 / 7(71.4)$ & 6/7(85.7) & - \\
\hline Previously had hypnosis & $19(27.5)$ & $4(17.4)$ & $9(39.1)$ & $6(26.1)$ & 0.504 \\
\hline $\begin{array}{l}\text { Number of prior hypnosis } \\
\text { sessions, median [IQR }{ }^{\ddagger}\end{array}$ & $2.5[1 ; 5]$ & $2.5[1 ; 9.5]$ & $3[2 ; 5]$ & $2[1 ; 4]$ & - \\
\hline $\begin{array}{l}\text { Pain score prior to patch } \\
\text { application } \S \text {, mean } \pm S D\end{array}$ & $3.7 \pm 2.4$ & $4.5 \pm 2.3$ & $3.2 \pm 2.6$ & $3.4 \pm 2.2$ & 0.196 \\
\hline $\begin{array}{l}\text { Anxiety score prior to patch } \\
\text { application§, mean } \pm \text { SD }\end{array}$ & $2.6 \pm 2.9$ & $3.9 \pm 3.1$ & $2.3 \pm 2.7$ & $1.9 \pm 2.7$ & 0.096 \\
\hline \multicolumn{6}{|c|}{ Abbreviations : SD standard deviation IQR : interquartile range } \\
\hline \multicolumn{6}{|c|}{${ }^{\dagger}$ Among the 25 patients with a history of cardiovascular disease. } \\
\hline \multicolumn{6}{|c|}{ ‡ Among the 19 patients who previously had hypnosis } \\
\hline \multicolumn{6}{|c|}{$\begin{array}{l}\S \text { Numerical rating scale (NRS). The NRS score ranges from } 0 \text { to } 10 \text {, with } 0 \text { indicating no pain/anxiety } \\
\text { and } 10 \text { the worst imaginable pain/anxiety. Higher scores on the NRS scale indicate a higher intensity } \\
\text { of pain/anxiety }\end{array}$} \\
\hline
\end{tabular}

In the music group, 14 patients $(60.9 \%)$ chose easy-listening music, $5(21.7 \%)$ chose classical music, and $3(13 \%)$ chose relaxing music. Twenty patients $(90.9 \%)$ listened the hypnotic message in its entirety. A cold pack was applied by 18 patients $(78.3 \%)$ in the standard group, $17(73.9 \%)$ in the hypnotic group and, $20(87.0 \%)$ in music group $(p=0.652)$.

\section{Primary outcome}

Overall, there was no significant difference in pain scores between groups after application of the capsaicin patch $(p=0.355)$ (Table 2$)$. 
Table 2

Pain and anxiety before and after application of a capsaicin patch and duration of patch application as perceived by the patient in the three study arms

\begin{tabular}{|c|c|c|c|c|}
\hline & \multirow{2}{*}{$\begin{array}{l}\text { STANDARD } \\
\mathrm{N}=23\end{array}$} & \multirow{2}{*}{$\begin{array}{l}\text { HYPNOSIS } \\
\mathrm{N}=23\end{array}$} & \multirow{2}{*}{$\begin{array}{l}\text { MUSIC } \\
N=23\end{array}$} & \multirow{2}{*}{$\begin{array}{l}\text { p- } \\
\text { value }\end{array}$} \\
\hline & & & & \\
\hline & Mean $\pm S D$ & Mean \pm SD & $\begin{array}{l}\text { Mean } \pm \\
\text { SD }\end{array}$ & \\
\hline \multicolumn{5}{|l|}{ Pain $\S$} \\
\hline Before application & $4.5 \pm 2.3$ & $3.2 \pm 2.6$ & $3.4 \pm 2.2$ & 0.196 \\
\hline Immediately after application & $4 \pm 2.2$ & $3.0 \pm 2.4$ & $3.8 \pm 2$ & $\begin{array}{l}0.245 \\
*\end{array}$ \\
\hline After patch removal & $6.4 \pm 2.9$ & $4.6 \pm 2.9$ & $5.3 \pm 2.6$ & $\begin{array}{l}0.355 \\
*\end{array}$ \\
\hline 72 hours after patch removal & $3.4+/-2.9$ & $3.2+/-2.9$ & $2.1+/-2.7$ & $\begin{array}{l}0.461 \\
\star\end{array}$ \\
\hline \multicolumn{5}{|l|}{ Anxiety $\S$} \\
\hline Before application & $3.9 \pm 3.1$ & $2.3 \pm 2.7$ & $1.9 \pm 2.7$ & 0.100 \\
\hline Immediately after application & $4.0 \pm 3.2$ & $2.3 \pm 2.7$ & $1.9 \pm 2.7$ & $\begin{array}{l}0.783 \\
\star\end{array}$ \\
\hline After patch removal & $4.2 \pm 3.2$ & $1.2 \pm 2.5$ & $1.7 \pm 2.5$ & $\begin{array}{l}0.010 \\
*\end{array}$ \\
\hline $\begin{array}{l}\text { Duration of patch application as perceived by the } \\
\text { patient, minutes }\end{array}$ & $63.8 \pm 10.7$ & $44.6 \pm 16.5$ & $\begin{array}{l}49.3 \pm \\
14.7\end{array}$ & 0.002 \\
\hline \multicolumn{5}{|l|}{ Abbreviations : SD standard deviation } \\
\hline \multicolumn{5}{|c|}{$\begin{array}{l}\S \text { Numerical rating scale (NRS). The NRS score ranges from } 0 \text { to } 10 \text {, with } 0 \text { indicating no pain/anxiety } \\
\text { and } 10 \text { the worst imaginable pain/anxiety. Higher scores on the NRS scale indicate a higher intensity } \\
\text { of pain/anxiety }\end{array}$} \\
\hline * Adjusted for values prior to patch application & & & & \\
\hline
\end{tabular}

\section{Secondary outcomes}

For anxiety (Table 2), scores were significantly different between groups after patch removal $(p=0.010)$. Compared to standard application, anxiety was significantly lower in the hypnosis group after the application ( $p=0.007$ after Bonferroni adjustment). There was no significant difference between the standard and music arms, or between the hypnosis and music arms $(p=0.271$ and $p=0.423$ respectively after Bonferroni adjustment). There was also a significant difference between groups in terms of the 
perceived duration of the application ( $p=0.002$, Table 2$)$, with a significant difference between the standard and hypnosis arms ( $p<0.001$ after Bonferroni adjustment), and between the standard and music arms ( $p<0.001$ after Bonferroni adjustment), but not between the hypnosis and music arms $(p=$ 0.424 after Bonferroni adjustment).

\section{Discussion}

This study aimed to address the adverse effects that may occur during application of a capsaicin patch (e.g. burning or tingling sensation, intensification of pain) by proposing a standardized hypnotic message to be played while the patch was in place. Even if expected results on pain reduction were not obtained, patients who listened to the hypnosis recording had a significantly lower level of anxiety compared to the standard patch application procedure. We included a group that listened to music during the application of the patch since the effects of music on pain and anxiety have previously been demonstrated [15] and could serve as a reference to explain the psychological and neurophysiological mechanisms at play in this process. Our study precludes any conclusions regarding the efficacy of music on anxiety. To the best of our knowledge, our study is the first to assess the impact of a standardized hypnotic message on selfreported pain and anxiety. What is innovative in this approach is that the hypnosis session offered to patients was recorded. Indeed, in normal clinical practice, the sessions are "tailor-made", individualized for each patient during a therapeutic encounter. Here, in a certain way, we can say that hypnosis was evaluated in its technical dimension, without the relationship, since the session was standardized. The aim was to evaluate a practice from which patients could benefit in all cases, even when the caregiver is not trained to accompany them with hypnosis.

We did not observe any difference in pain scores between groups, which is surprising in view of the results obtained with hypnosis for pain [16]. Perhaps the personalized approach to hypnosis, which more closely corresponds to the reality of hypnosis practices in real life, might have yielded a more marked difference. Additionally, the metaphor used in the message was that of going walking in the mountains and bathing in a mountain lake. It would also be interesting to assess the effect of using specific analgesic suggestions, such as the glove anesthesia method, or modulation of pain through mental imagery. This strategy differs from the simple suggestion of coolness, and might help patients to experience less pain.

We observed that pain and anxiety scores tended to be lower before patch application in patients in the hypnosis and music arms, as compared to those in the standard treatment arm. This observation could be explained by a possible placebo effect when the patient is informed of the treatment group they have been assigned to by the randomization process $[17,18]$. Indeed, the patient was informed of the allocated treatment group before the first evaluation of pain and anxiety. A previous study has shown that labelling the induction process as "hypnosis" led to a significant increase in patient suggestibility, compared to when it was just called "relaxation" [19]. The patients' expectations of the therapeutic accompaniment appear to be a key factor in their subjective experience of a potentially painful and anxiogenic care process. 
It is noteworthy that patients in the hypnosis and music arms had a subjective impression that the patch was in place for a much shorter time compared to patients in the standard treatment arm. This distorted perception of time can be explained by several factors. Firstly, by the simple fact of distracting attention by listening to, and concentrating on the audio recording. Secondly, temporal distortion has been described as a characteristic of the hypnotic phenomenon [20,21]. We believe that this finding of temporal foreshortening is important, as it contributes to limiting the discomfort caused by exposure to the patch, in comparison with patients who are treated in the standard manner, without accompaniment.

\section{Study limitations}

It should be underlined that all patients included in this study had previously had a capsaicin patch applied, and were thus attending for a second application. Although the purpose of this was to ensure a homogeneous population, it is possible that the patient was already familiar with the sensations, and could anticipate them once informed of their randomization group. Secondly, anxiety was not mesuread by a commonly used instruments such as the State form of the Spielberger State Trait Anxiety Inventory (STAI). However, the STAI comprises 20 items, and in our study, anxiety was measured at several timepoints over a short period of time. Therefore, the STAI did not seem to be the most suitable tool for our study and we opted instead for a numerical rating scale. Finally, our study failed to show any superiority of hypnosis over music, probably due to a lack of statistical power, since the study was designed to show a difference between the hypnosis group and the standard procedure.

\section{Clinical implications}

Patients' expectations of analgesic therapy, maintaining an acceptable level of anxiety, and the perception of the passage of time during the delivery of healthcare, all appear to be determinant in shaping the patient's overall subjective experience. Our study focused on cancer patients with at least one previous application of a capsaicin patch. Since the standardized hypnosis message is easy to use, without the need for additional human resources, its use could easily be generalized to all patients receiving treatment with a capsaicin patch. It would be also interesting to investigate the same procedure among patients who were having a patch applied for the first time and who had never previously been exposed to capsaicin.

\section{Conclusions}

In this study, although it had no effect on the perceived level of pain as compared to standard procedures, listening to a standardized hypnotic message during application of a capsaicin patch was found to lower anxiety. This study opens interesting avenues for improving the comfort of patients during treatment. These findings warrant further evaluation in other indications where treatments may generate pain or anxiety using specific analgesic suggestions rather than suggestions only based on sensations. Using recorded standardized hypnotic messages and procedures could enable the use of this approach in healthcare centres with limited facilities. 


\section{Declarations}

\section{Ethics approval and consent to participate}

This study adhered to the principles of the Declaration of Helsinki and guidelines of Good Clinical Practice. The safety and ethical conformity of the study have been reviewed and approved by the Ethics Committee (Comité de Protection des Personnes, CPP Est III) on 03/05/2016 under the number 16.03 .06 and by the National agency for the safety of medicines and health products on 22/04/2016 under the number 160228B-32. The study was also registered with the ClinicalTrials.gov Registry on 04/07/2016 under the number NCT02822625. All participants provided written informed consent.

\section{Consent for publication}

Not applicable

\section{Availability of data and materials}

The datasets used and/or analysed during the current study are available from the corresponding author on reasonable request.

\section{Competing interests}

The authors declare that they have no competing interests

\section{Funding}

This study was supported by AFIC (French Association of Cancer Nurses) and the private research fund of the Institut de Cancérologie de Lorraine.

\section{Authors' contributions}

$\mathrm{RE}$ and $\mathrm{ML}$ made substantial contributions to the conception, interpreted the patient data and drafted the work. AH and NC had made substantial contributions to acquisition of data. AB made substantial contributions to the conception and drafted the work. SJ made substantial contributions to the conception, analyzed the data and was a contributor in writing the manuscript. CHS made substantial contributions to the conception. All authors approved the final manuscript and agreed both to be personally accountable for the author's own contributions and to ensure that questions related to the accuracy or integrity of any part of the work, even ones in which the author was not personally involved, are appropriately investigated, resolved, and the resolution documented in the literature

\section{Acknowledgements}

We thank Catherine Lamouille for useful discussion and Fiona Ecarnot, PhD (EA3920, University of Franche-Comté) for editorial assistance and review. 


\section{References}

1. Pickering G, Martin E, Tiberghien F, Delorme C, Mick G: Localized neuropathic pain: an expert consensus on local treatments. Drug Des Devel Ther 2017, 11:2709-2718.

2. Mick G, Correa-Illanes G: Topical pain management with the $5 \%$ lidocaine medicated plaster-a review. Curr Med Res Opin 2012, 28(6):937-951.

3. Wallace M, Pappagallo M: Qutenza(R): a capsaicin $8 \%$ patch for the management of postherpetic neuralgia. Expert Rev Neurother 2011, 11(1):15-27.

4. Tiberghien-Chatelain F, Laventurier S, Piccand V, Lajoie JL, Lassauge F: Efficacité du patch de capsaïcine 8\% Qutenza ${ }^{\circledR}$ sur les 26 premiers patients traités au CHU de Besançon [Efficacy of the Qutenza ${ }^{\circledR}$ capsaicin $8 \%$ patch in the first 26 patients treated at the University Hospital of Besançon]. Douleurs : Evaluation - Diagnostic - Traitement 2014, 15(6):288-303.

5. Kennedy WR, Vanhove GF, Lu SP, Tobias J, Bley KR, Walk D, Wendelschafer-Crabb G, Simone DA, Selim MM: A randomized, controlled, open-label study of the long-term effects of NGX-4010, a highconcentration capsaicin patch, on epidermal nerve fiber density and sensory function in healthy volunteers. J Pain 2010, 11(6):579-587.

6. Anand P, Bley K: Topical capsaicin for pain management: therapeutic potential and mechanisms of action of the new high-concentration capsaicin 8\% patch. Br J Anaesth 2011, 107(4):490-502.

7. Backonja M, Wallace MS, Blonsky ER, Cutler BJ, Malan P, Jr., Rauck R, Tobias J, Group N-CS: NGX4010, a high-concentration capsaicin patch, for the treatment of postherpetic neuralgia: a randomised, double-blind study. Lancet Neurol 2008, 7(12):1106-1112.

8. Blair HA: Capsaicin 8\% Dermal Patch: A Review in Peripheral Neuropathic Pain. Drugs 2018, 78(14):1489-1500.

9. Faymonville ME, Roediger L, Del Fiore G, Delgueldre C, Phillips C, Lamy M, Luxen A, Maquet P, Laureys S: Increased cerebral functional connectivity underlying the antinociceptive effects of hypnosis. Brain Res Cogn Brain Res 2003, 17(2):255-262.

10. Kendrick C, Sliwinski J, Yu Y, Johnson A, Fisher W, Kekecs Z, Elkins G: Hypnosis for Acute Procedural Pain: A Critical Review. Int J Clin Exp Hypn 2016, 64(1):75-115.

11. Jafarizadeh H, Lotfi M, Ajoudani F, Kiani A, Alinejad V: Hypnosis for reduction of background pain and pain anxiety in men with burns: A blinded, randomised, placebo-controlled study. Burns 2018, 44(1):108-117.

12. Roberts RL, Kekecs Z, Lazott L, Toor OH, Elkins GR: Hypnosis for burn-related pain: Case studies and a review of the literature. World $J$ Anesthesio/ 2017, 6(1):1-13.

13. Hawker GA, Mian S, Kendzerska T, French M: Measures of adult pain: Visual Analog Scale for Pain (VAS Pain), Numeric Rating Scale for Pain (NRS Pain), McGill Pain Questionnaire (MPQ), Short-Form McGill Pain Questionnaire (SF-MPQ), Chronic Pain Grade Scale (CPGS), Short Form-36 Bodily Pain Scale (SF-36 BPS), and Measure of Intermittent and Constant Osteoarthritis Pain (ICOAP). Arthritis Care Res (Hoboken) 2011, 63 Suppl 11:S240-252. 
14. Davey HM, Barratt AL, Butow PN, Deeks JJ: A one-item question with a Likert or Visual Analog Scale adequately measured current anxiety. J Clin Epidemiol 2007, 60(4):356-360.

15. Hole J, Hirsch M, Ball E, Meads C: Music as an aid for postoperative recovery in adults: a systematic review and meta-analysis. Lancet 2015, 386(10004):1659-1671.

16. Thompson T, Terhune DB, Oram C, Sharangparni J, Rouf R, Solmi M, Veronese N, Stubbs B: The effectiveness of hypnosis for pain relief: A systematic review and meta-analysis of $\mathbf{8 5}$ controlled experimental trials. Neurosci Biobehav Rev 2019, 99:298-310.

17. Goffaux P, Redmond WJ, Rainville P, Marchand S: Descending analgesia-when the spine echoes what the brain expects. Pain 2007, 130(1-2):137-143.

18. Marchand S, Gaumond I: Effets placebo et nocebo dans le traitement de la douleur : leur présence est inévitable mais leurs actions sont modulables [Placebo and nocebo effects in pain treatment: their presence is inevitable but their action can be modulated]. Douleur et Analgésie 2014, 27(4):198-202.

19. Gandhi B, Oakley DA: Does 'hypnosis' by any other name smell as sweet? The efficacy of 'hypnotic' inductions depends on the label 'hypnosis'. Conscious Cogn 2005, 14(2):304-315.

20. Bowers KS, Brenneman HA: Hypnosis and the perception of time. Int J Clin Exp Hypn 1979, 27(1):2941.

21. Schwartz W: Time and context during hypnotic involvement. Int J Clin Exp Hypn 1978, 26(4):307316.

\section{Figures}

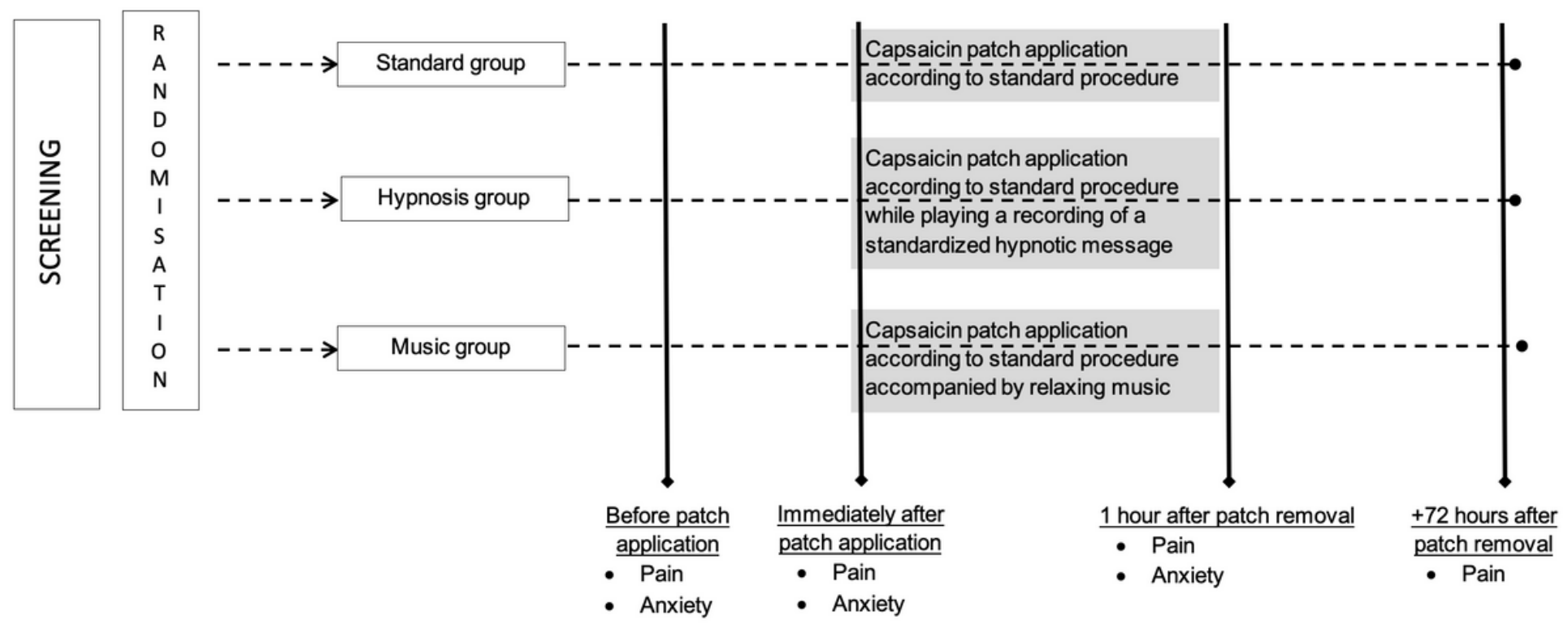

Figure 1

Flowchart of the study design 


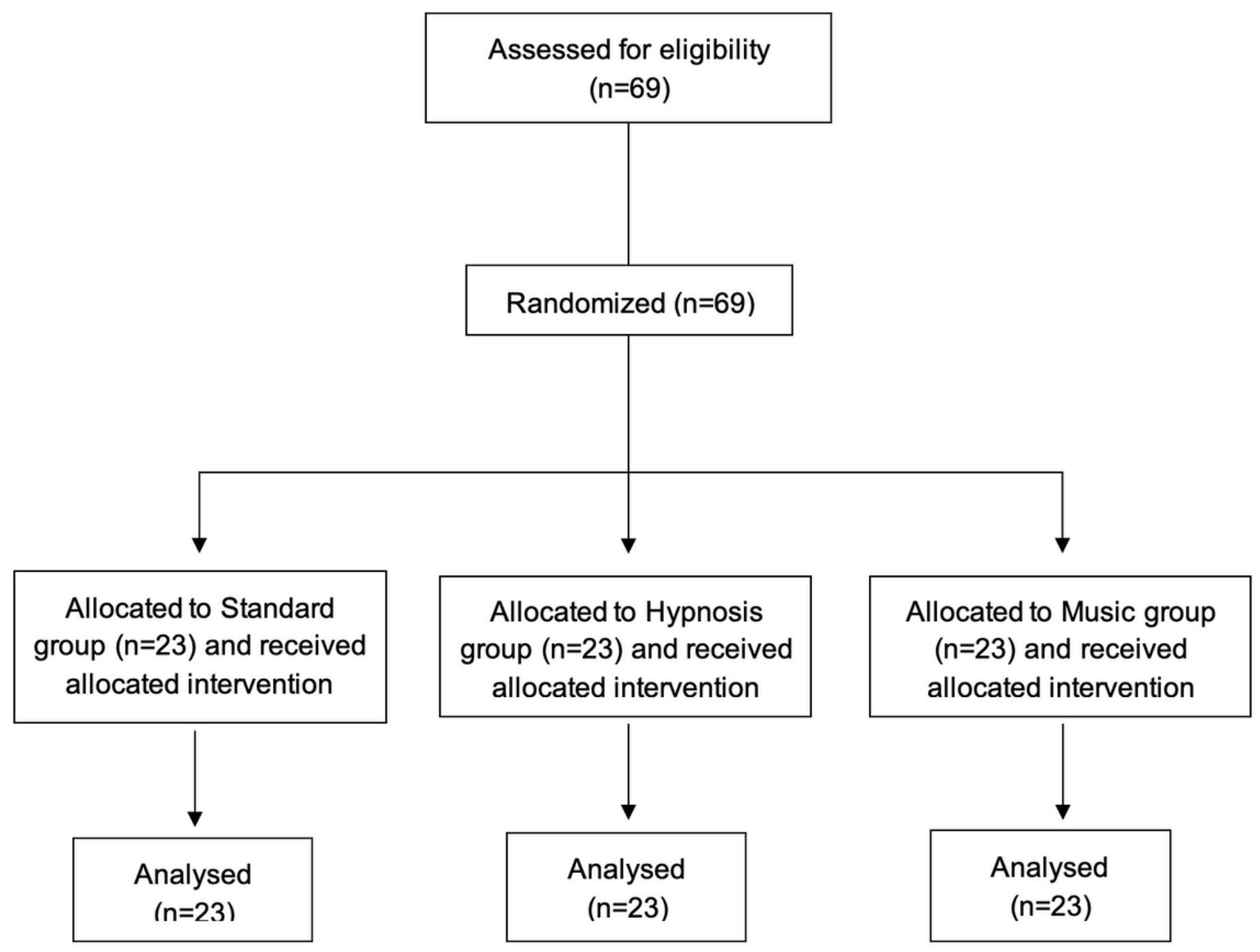

Figure 2

Flow Diagram 